\title{
Description of a robust interception trap for collecting airborne arthropods in climatically challenging regions
}

\author{
ROGER FARROW ${ }^{1}$ and PENELOPE GREENSLADE ${ }^{2,3 *}$ \\ ${ }^{1}$ Tilembaya, 777 Urila Road, Urila, NSW 2620, Australia \\ ${ }^{2}$ Environmental Management, University of Ballarat, Ballarat, VIC 3350, Australia \\ ${ }^{3}$ Botany and Zoology, Department of Biology, Australian National University, GPO, ACT 0200, Australia \\ *Corresponding author: Pgreenslade@staff.ballarat.edu.au
}

\begin{abstract}
An interception trap to collect airborne arthropods under extreme weather conditions is described. The trap, constructed from durable materials, is operated by wind pressure. It consists of a funnel of fine brass gauze mounted inside a cylinder of stainless steel that rotates into the wind on a mast at $1.5 \mathrm{~m}$ from the ground. The gauze funnel terminates in a removable, propanol-filled, collecting bottle into which airborne material accumulates. The counterbalanced cylinder rotates around a central shaft on roller bearings and faces into the wind. Two traps were successfully operated continuously for four and five years, respectively, on sub-Antarctic Macquarie Island and have collected large numbers of airborne arthropods and other biological material over this period.
\end{abstract}

Received 7 September 2012, accepted 15 November 2012, first published online 8 March 2013

Key words: brass gauze, immigrants, invertebrates, Macquarie Island, stainless steel, wind

\section{Introduction}

Many species of arthropod are transported by wind for long distances over land and sea and can fall out on remote islands (Johnson 1978). Their chances of establishing on islands are often low because environmental conditions are usually unfavourable (e.g. an unsuitable climate or lack of habitats and host plants) (Farrow 1984). However, should conditions change as a result of climatic change, some immigrant species may be able to survive and establish. This is likely to occur where low temperatures are currently limiting survival on sub-Antarctic islands. The mean temperature of some of these islands rose significantly during the 20th century (Tweedie \& Bergstrom 2000) making it more likely that new introductions could establish. One of these islands, Macquarie Island, has been subject to detailed studies of its fauna and flora in relation to the expansion of populations of accidental introductions and to the impact of tourism (Selkirk et al. 1990, PWS 2006, Greenslade 2006). However, it was not known what, if any, introductions were occurring naturally, as a result of wind-assisted transport from Australia and New Zealand to the north, although suitable wind trajectories do exist (Pierrehumbert et al. 1984). For example, adults of the noctuid moth, Agrotis ipsilon (Hufn.), are occasionally collected on Macquarie Island when attracted to the station lights, but do not breed on the island, and have originated from either Australia or New Zealand (Watson 1967, Greenslade et al. 1999, Potts 1997).

J.L. Gressitt, the pioneer of aerial sampling over the oceans and on remote islands, had previously attempted to sample insects on Macquarie Island using large muslin nets suspended from poles (modified Malaise traps) (Gressitt et al. 1960), but these rapidly disintegrated in the severe weather conditions experienced on the island, namely the high winds, driving horizontal rain and salt spray. Other methods which have been used to collect wind transported particles in severe southern climates include upturned Frisbees, with or without marbles, but they are not able to collect airborne insects. Malaise traps would not survive even one day on the sites at which we had the wind traps because of the strong winds. Whilst 'yellow pans' half filled with soapy water, have been used on Macquarie Island in the past and have collected a range of very locally distributed invertebrates that only move close to the ground, but they have to be changed twice a day, and so are expensive in fieldwork time.

This paper describes the construction of a heavy duty trap, two of which were in operation at different sites on Macquarie Island from 1991 and 1992, until 1995. The climatic conditions on Macquarie Island (54 $\left.30^{\circ} \mathrm{S}, 158^{\circ} 57^{\prime} \mathrm{E}\right)$, are sub-Antarctic and severe in some respects. The island is remote from other land masses and, although the climate is relatively equable with small variation in temperature seasonally and diurnally, it experiences persistent, strong, prevailing west to north-westerly winds. As Macquarie Island lies in the path of cyclones formed in the mid latitudes over warm ocean currents which move south-eastwards and intensify (De Lisle 1965), it regularly experiences high winds with violent gusting and occasional gale force winds. The average wind speed on Macquarie Island is $9.3 \mathrm{~m} \mathrm{~s}^{-1}$ and gale force winds are recorded on over 70 days per annum with maximum gusts up to $36.7 \mathrm{~m} \mathrm{~s}^{-1}$ (Selkirk et al. 1990). Rainfall is fairly evenly distributed throughout the year at 
a
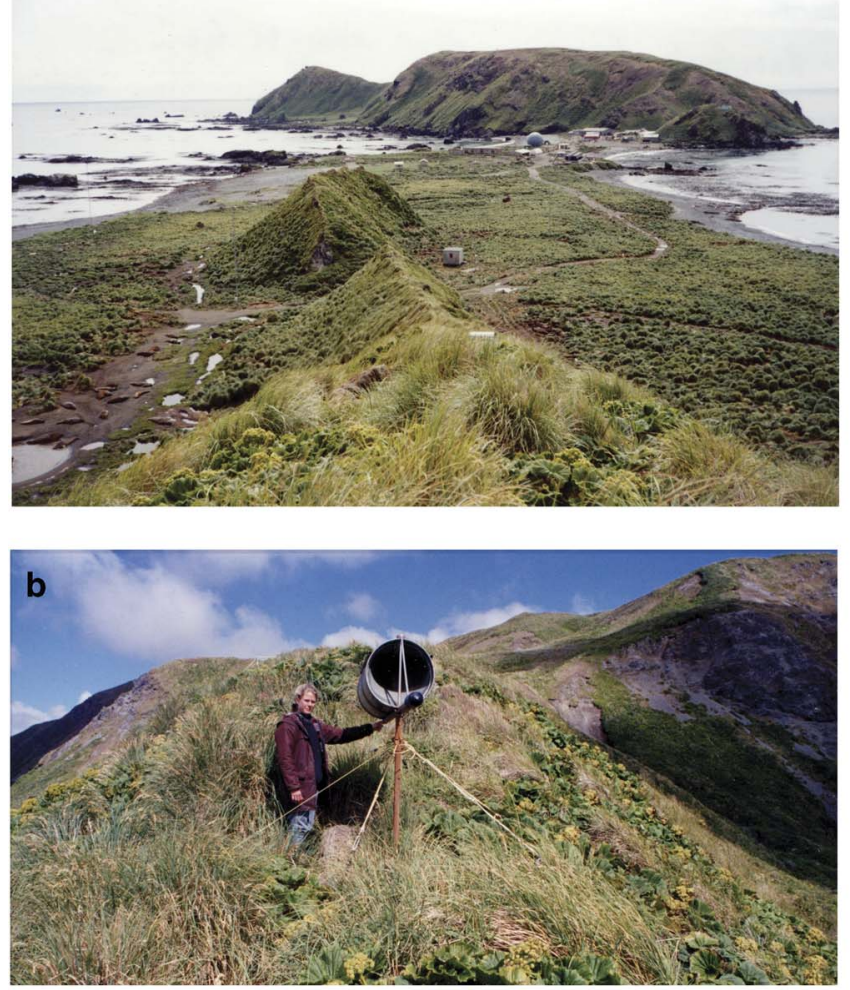

C

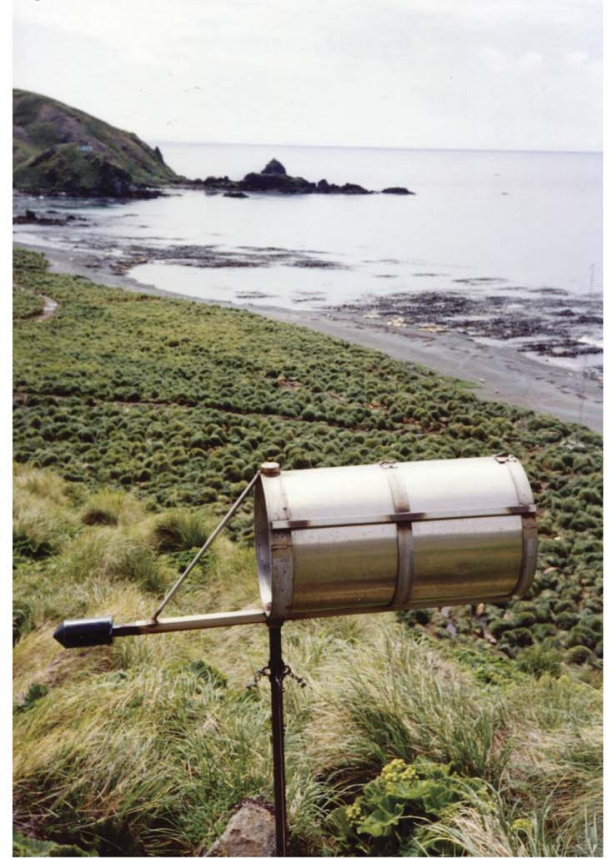

d
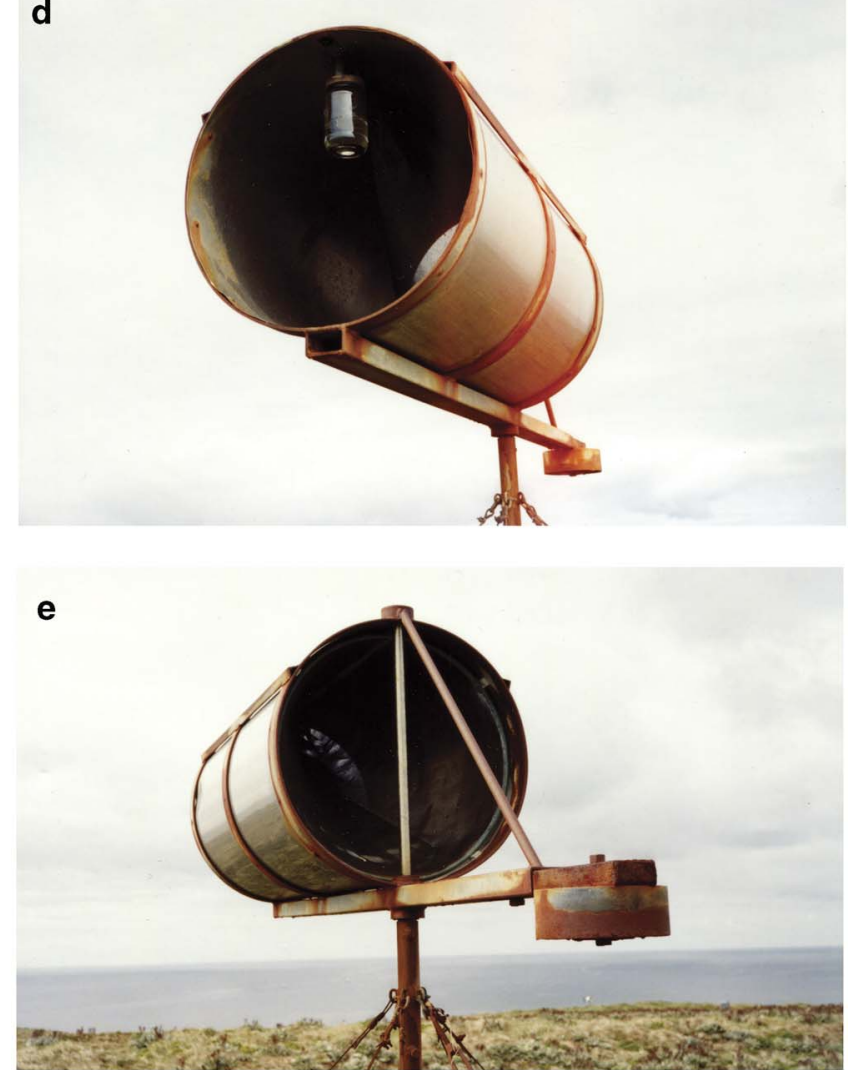

$\mathbf{f}$

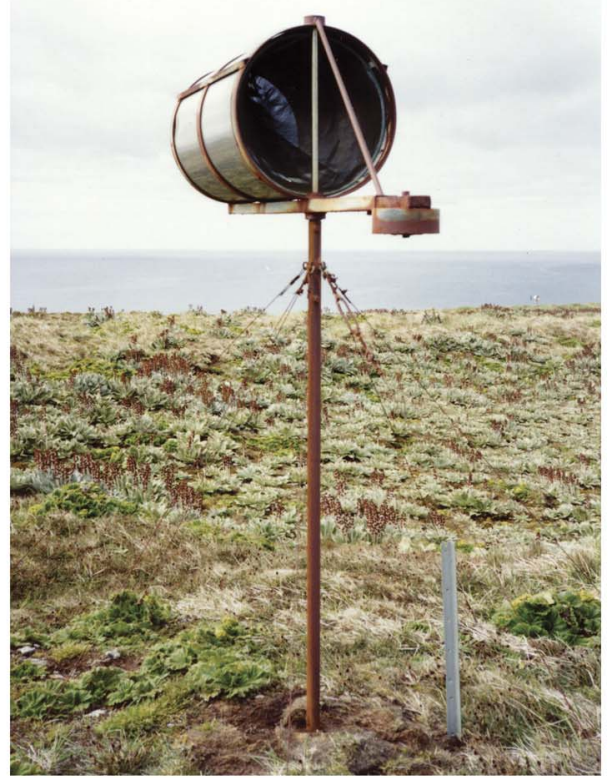

Fig. 1. a. View to north of Macquarie Island from above Razorback Hill (RBH). RBH trap in foreground, North Head on peninsula in background where trap is located at highest point. b. Field Officer standing beside RBH trap, view looking south. c. Side view of RBH trap. d. Back view of RBH trap. e. Front view of RBH trap. f. Wind trap on North Head, Macquarie Island. This penultimate model lacks the vane and has a different type of counterweight. 


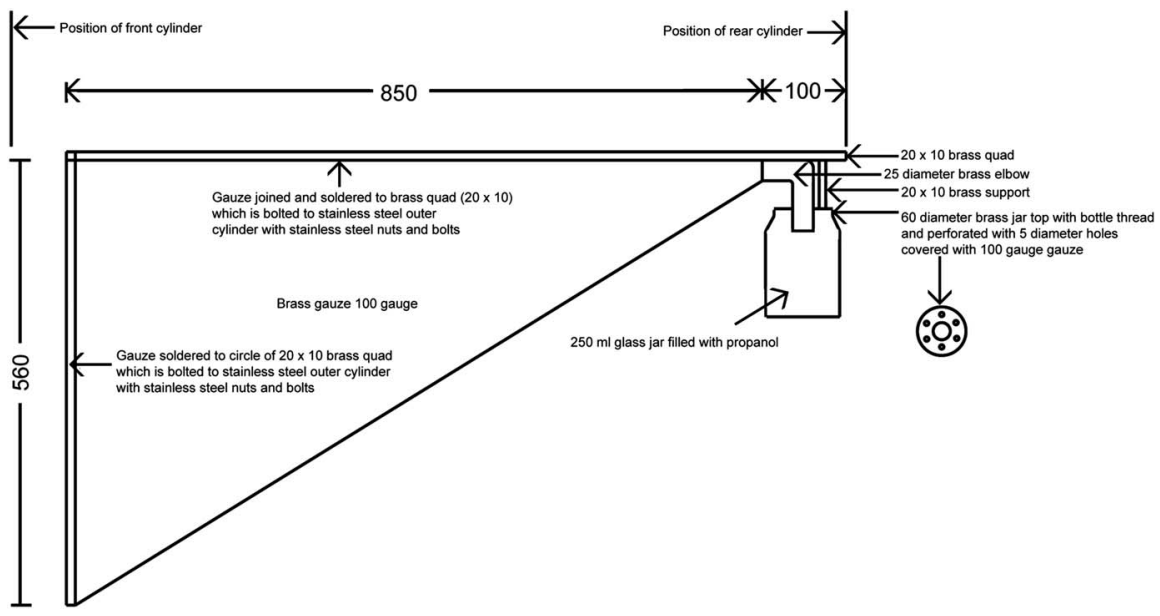

Fig. 2. The removable gauze funnel in longitudinal section. All measurements in millimetres.

$895 \mathrm{~mm}$ per annum. Mean daily maximum temperatures are $8.8^{\circ} \mathrm{C}$ in summer and $4.9^{\circ} \mathrm{C}$ in July, with minima of $5.3^{\circ} \mathrm{C}$ in summer and $1.5^{\circ} \mathrm{C}$ in winter. Any trap therefore would need to be built of robust materials. Prototype traps introduced in 1989 and 1990 failed to last a season because the materials used were not strong enough to withstand the extreme weather conditions. In 1989 CSIRO (Commonwealth Scientific and Industrial Organisation), in collaboration with Tasmanian National Parks and Wildlife Service and Australian Antarctic Division, set up a reliable, wind-operated interception trap on Macquarie Island to collect airborne arthropods and other biological material throughout the year with samples being removed at weekly intervals (Fig. 1a, b \& f). This paper describes the construction of a heavy duty trap, two of which were in operation at different sites on Macquarie Island from 1991 and 1992 until 1995.

\section{Trap design and construction}

High quality, heavy duty, stainless steel is used for the trap which comprises a removable, asymmetric funnel of fine brass gauze, suspended within a reinforced cylinder of

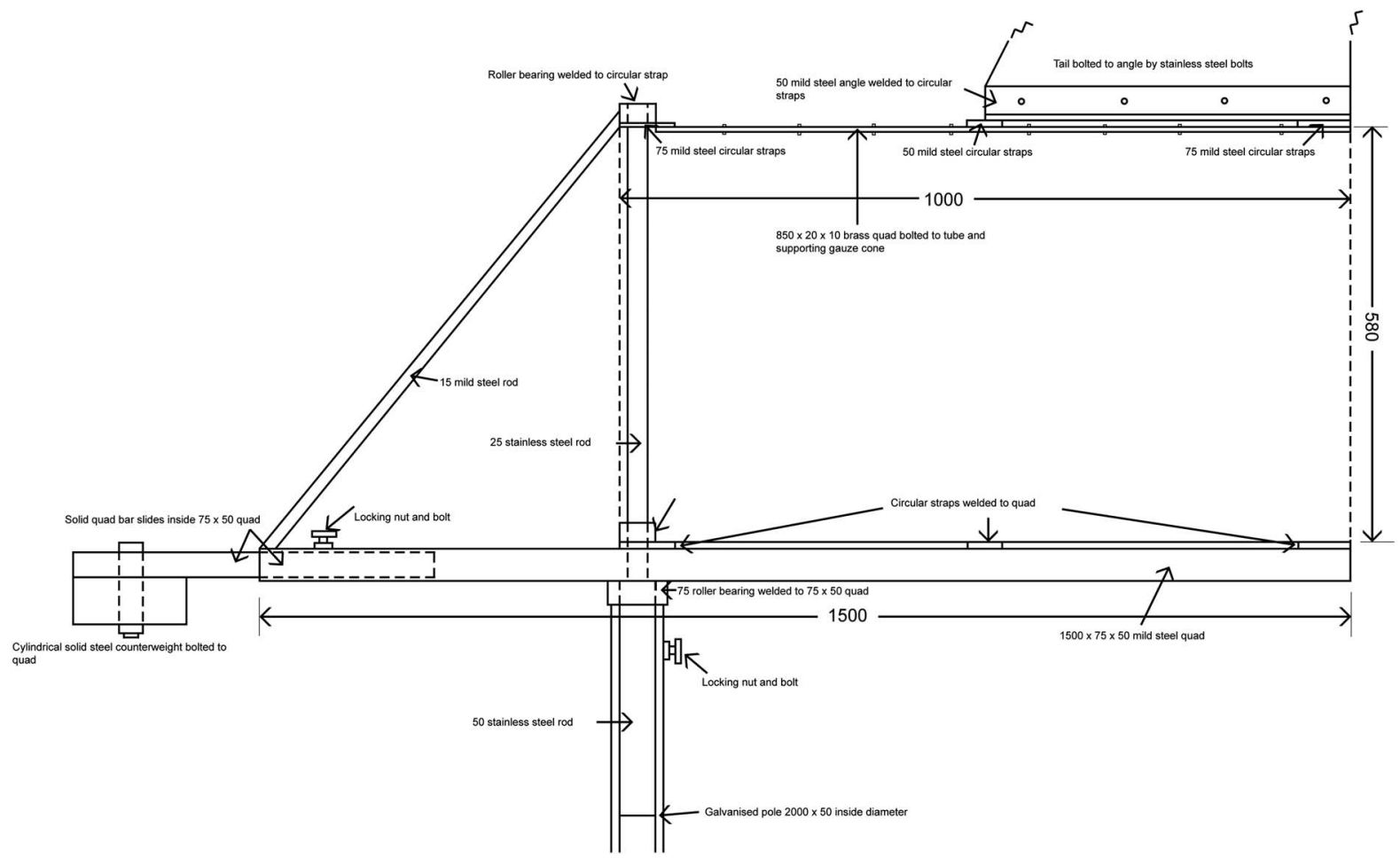

Fig. 3. The whole trap in longitudinal section. All measurements in millimetres. 


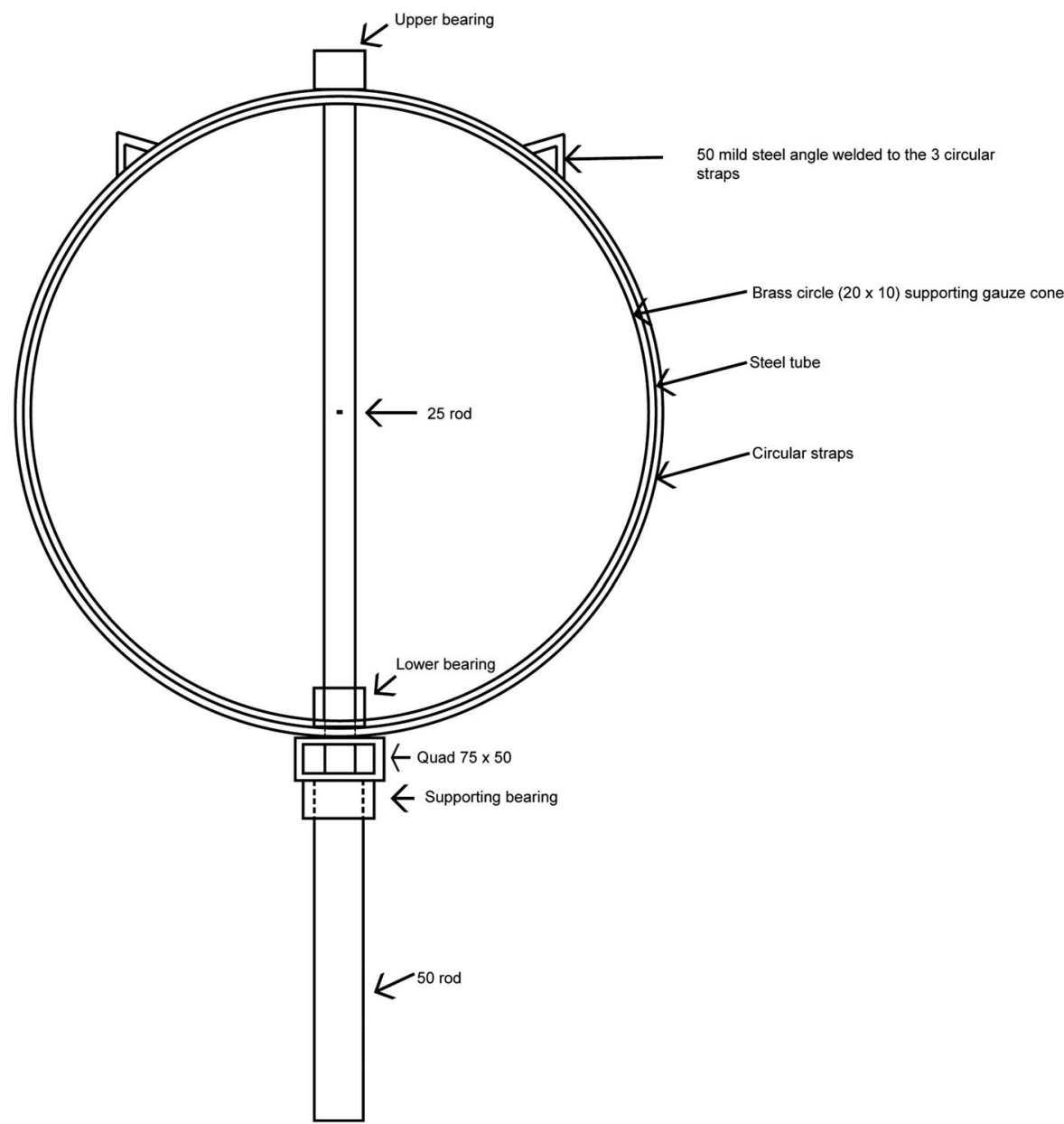

Fig. 4. Cross section of the front of the trap. All measurements in millimetres. stainless steel. The cylinder rotates into the wind on heavy duty bearings and is counterbalanced to allow smooth rotation (Fig. 1c). Airborne material is forced through the funnel by natural wind pressure into a collecting jar filled with propanol to preserve the collected material. Propanol is preferred to ethanol because it evaporates more slowly. The steel cylinder and asymmetric funnel prevent rain from being driven into the collecting jar. The trap is supported on a $2 \mathrm{~m}$ galvanised pole buried in concrete to a depth of c. $0.5 \mathrm{~m}$ and braced with heavy duty, stainless woven wire stays on adjustable marine-type shackles at about $1.5 \mathrm{~m}$ from the ground (Fig. 1f). The height of the pole was determined by the height that allowed easy changing of the collection vessel and also, since the trap was extremely heavy, could be safely supported. Even so, the erection of the two traps involved considerable expert station personnel.

The mouth of the funnel is $0.25 \mathrm{~m}^{2}$ in cross section (diameter $560 \mathrm{~mm}$ ). The aperture of $0.25 \mathrm{~m}^{2}$ was a compromise between the advantages of filtering as large a volume of air as possible and the need to produce a trap of manageable size and weight. The open end of the gauze funnel is soldered to a circle of quadrangular brass $(20 \times 10 \mathrm{~mm})$. The join in the gauze for the funnel is made along the horizontal top surface and the two edges are soldered to a $1000 \mathrm{~mm}$ long brass quadrangular $(20 \times 10 \mathrm{~mm})$ which also supports the collecting jar (Fig. 2). The longitudinal and circular brass quadrangulars are screwed at intervals to the surrounding cylinder with stainless steel nuts and bolts. The funnel terminates in a $25 \mathrm{~mm}$ aperture into which a $25 \mathrm{~mm}$ copper bend is soldered. This bend passes through a $60 \mathrm{~mm}$ brass lid with a bottle thread to which a standard $250 \mathrm{~cm}^{3}$ glass jar can be screwed and replaced as required. The tube is soldered to the lid which is perforated with a number of holes which are covered with a disc of fine brass gauze. The holes allow air to escape from the jar and facilitate the passage of some air and the filtered airborne material into the collecting jar.

The stainless steel cylinder is slightly larger than the funnel and is $1000 \mathrm{~mm}$ long. It is braced by three circular mild steel straps which are welded to a mild steel quadrangular base $(1500 \times 75 \times 50 \mathrm{~mm})$ (Figs 2, $3 \& 4)$. The cylinder is riveted to the circular straps. The straps are also braced by two lengths of $50 \mathrm{~mm}$ angle in mild steel which prevent the tube from twisting or vibrating in high wind. Three heavy-duty, sealed roller bearings support the front of the trap and allow it to rotate smoothly. The lower 
tapered bearing takes a $50 \mathrm{~mm}$ stainless steel rod, which sits on a galvanised pole with an internal diameter of $50 \mathrm{~mm}$. The two other bearings are welded to the top and inside of the tube respectively and support a $25 \mathrm{~mm}$ stainless steel rod which is welded to the lower $50 \mathrm{~mm}$ rod. This rod passes through a hole in the quadrangular (Fig. 4).

The quadrangular projects $500 \mathrm{~mm}$ from the front of the trap which is further braced, as shown in Fig. 3, with a $15 \mathrm{~mm}$ mild steel rod welded to the upper bearing. A solid quadrangular bar supports an adjustable counterweight and slides within the larger hollow quadrangular and is anchored by a lock nut. The weight of this counterweight must be measured after the trap is constructed with c. $200 \mathrm{~mm}$ of the counterweight supporting rod projecting from the quadrangular to allow for minor adjustments to balance the trap. A vane measuring about $300 \times 500 \mathrm{~mm}$ is bolted to a length of mild steel angle welded to the top rear section of the trap to ensure the trap faces into the wind (Fig. 1f). The vanes were actually lost during shipments and are not attached to the traps installed on Macquarie Island (Fig. 3). There are some small differences in the way in which the counterweight is attached in the two traps (Fig. 1c \& f). All mild steel fittings were heavily galvanised before final assembly of the trap.

\section{Operation and results}

Two traps were constructed at the Division of Entomology workshop, the first in 1991 and the second in 1992, and they were installed at separate sites on Macquarie Island: Razorback Ridge and North Head, respectively (Fig. 1a).

\section{Discussion}

Suction traps decrease in efficiency as wind speed increases because less air passes into the funnel and they rarely trap strong-flying insects because they can avoid the trap. Moreover suction traps require mains power, are mechanically complicated and not suitable for operating at remote sites. Our traps are passive devices relying on wind pressure to intercept airborne material. These traps allow calculations of the suction flow and/or wind speed so that aerial density and migration rates of airborne material can be estimated (Southwood 1966).

Traps operating too close to the ground will mainly intercept material which is flying in the surface boundary layer, but may also trap material which has descended from the upper air after a migration (Farrow 1986). Nightflying native insects can be distinguished from immigrants by an analysis of accompanying weather systems and also, naturally, by identifying all specimens to species (Farrow 1984). Since a dilution of airborne material occurs (Farrow 1984) the probability of recovering immigrants is low. On Macquarie Island, a low frequency of suitable wind trajectories exists from Australia and New Zealand.
However, Agrotis ipsilon from New Zealand has been collected several times on the island and so detection of arthropod immigrants seems probable using the wind traps described here.

The problems encountered during four to five years of operation have been: evaporation of propanol from the jars when they were not changed frequently enough; blocking of the exit tube from the cone with grass seed heads which necessitates frequent inspection and clearing during the grass seeding season; a tear in one of the gauze funnels after four years of operation, which was repaired with solder; and progressive but slow rusting of the galvanised fittings.

The success of the trap is supported by the fact that over 3000 invertebrates (nearly all resident species) were collected in the years of operation of two of these traps on Macquarie Island (Potts 1997, Farrow \& Greenslade, unpublished data). A report and analyses of the results is underway (Hawes \& Greenslade in press). The development and installation of such traps would have been a useful addition to those used in the BIOTA programme to detect propagules from distant and localized sources (Wynn-Williams 1992). In addition, such traps provide new biological information on the flight activity of indigenous species and contribute to our understanding of the biogeography and dispersal abilities of species of sub-Antarctic islands (Hawes \& Greenslade in press).

\section{Acknowledgements}

We thank staff of the Division of Entomology Workshop for constructing the traps and for helpful advice on design, Emma Nestor for preparation of Figs 2-4, and the Antarctic Scientific Advisory Committee and Antarctic Division for financial support to carry out this project. The constructive comments of the reviewers are also gratefully acknowledged.

\section{References}

De Lisle, J.G. 1965. The climate of the Auckland Islands, Campbell Island and Macquarie Island. Proceedings of the New Zealand Ecological Society, 12, 37-44.

FARROW, R.A. 1984. Detection of transoceanic migration of insects to a remote island in the Coral Sea, Willis Island. Australian Journal of Ecology, 9, 253-272.

FARROW, R.A. 1986. Interactions between synoptic scale and boundary layer meteorology on micro-insect migration. In DanthanARYANA, V.A., ed. Insect flight, dispersal and migration. Heidelberg: Springer, 185-195. Greenslade, P. 2006. The invertebrates of Macquarie Island. Kingston: Australian Antarctic Division, 326 pp.

Greenslade, P., Farrow, R.A. \& Smith, J.M.B. 1999. Long distance migration of insects to a sub-Antarctic island. Journal of Biogeography, 26, 1161-1167.

Gressitt, J.L., LeEch, R.E. \& O’Brien, C.W. 1960. The trapping of air-borne insects in the Antarctic area. Pacific Insects, 2, 549-555.

Hawes, T.C. \& Greenslade, P. In press. The aerial invertebrate fauna of subantarctic Macquarie Island. Journal of Biogeography.

Johnson, C.G. 1978. Migration and dispersal of insects by flight. London: Methuen, 763 pp. 
Pierrehumbert, C., Powell, F.A. \& Oliver, S. 1984. Continental transport of particulate matter between Australia and Macquarie Island. In Hartmann, H.F., O’Heare, J.N., Chioda, J. \& Gillis, R., eds. Proceedings of the Eighth International Clean Air Conference, Melbourne, May 1984. Olinda, Victoria: Clean Air Society of Australia and New Zealand 741-750.

Pоттs, T.W. 1997. Monitoring invertebrate migration and dispersal on subantarctic Macquarie Island. BSc Hons thesis, Institute of Antarctic and Southern Ocean Studies, University of Tasmania, 140 pp. [Unpublished.]

PWS (Parks and Wildlfie Service). 2006. Macquarie Island Nature Reserve and World Heritage Area Management Plan 2006. Hobart: Parks and Wildlife Service, Department of Tourism, Arts and Environment, $176 \mathrm{pp}$.
Selkirk, P.M., Seppelt, R.D. \& Selkirk, D.R. 1990. Sub-Antarctic Macquarie Island: environment and biology. Cambridge: Cambridge University Press, 285 pp.

Southwood, T.R.C. 1966. Ecological methods. London: Methuen, 391 pp. Tweedie, C.E. \& Bergstrom, D.M. 2000. A climate change scenario for surface air temperature at sub-Antarctic Macquarie Island. In Davison, W., Howard-Williams, C. \& Broady, P., eds. Antarctic ecosystems: models for wider understanding. Christchurch: Caxton Press, 272-281.

Watson, K.C. 1967. The terrestrial Arthropoda of Macquarie Island. ANARE Science Reports, Series B1, Zoology, No. 99, 1-90.

Wynn-Williams, D.D. ed. 1992. BIOTAS manual of methods for Antarctic terrestrial and freshwater research. Cambridge: Scientific Committee on Antarctic Research, 145 pp. 